\title{
Riverine evidence for isotopic mass balance in the Earth's early sulfur cycle
}

\author{
Mark A. Torres, ${ }^{1,2 *}$ Guillaume Paris,${ }^{1,3}$ Jess F. Adkins, ${ }^{1}$ Woodward W. Fischer ${ }^{1}$ \\ ${ }^{1}$ Division of Geological and Planetary Sciences, California Institute of Technology, \\ 1200E California Blvd, Pasadena, CA 91125, USA \\ ${ }^{2}$ Department of Earth, Environmental, and Planetary Sciences, Rice University \\ 6100 Main Street, Houston, TX 77005, USA \\ ${ }^{3}$ Centre de Recherches Pétrographiques et Géochimiques \\ 15 Rue Notre Dame des Pauvres, 54500 Vandœuvre-lès-Nancy, France \\ *To whom correspondence and requests for materials should be addressed; E-mail: mt61@ rice.edu.
}

During a time of negligible atmospheric $\mathrm{pO}_{2}$, Earth's early sulfur cycle generated a spectacular geological signal seen as the anomalous fractionation of multiple sulfur isotopic ratios. The disappearance of this signal from the geologic record has been hypothesized to constrain the timing of atmospheric oxygenation, though interpretive challenges exist. Asymmetry in existing $\mathrm{S}$ isotopic data, for example, suggest that the Archean crust was not mass balanced, with the implication that the loss of $\mathrm{S}$ isotope anomalies from the geologic record might lag the rise of atmospheric $\mathrm{O}_{2}$. Here, we present new $\mathrm{S}$ isotopic analyses of modern surface and groundwaters that drain Archean terrains in order to independently evaluate Archean S cycle mass balance. Natural waters contain sulfur derived from the underlying bedrock and thus can be used to ascertain its $S$ isotopic composition at scales larger than typical geological samples allow. Analyses of 52 water samples from Canada and South Africa suggest that the Archean crust was mass balanced with an average multiple $S$ isotopic composition equivalent to the bulk Earth. Overall, our work supports the hypothesis that the disappearance 


\section{of multiple $S$ isotope anomalies from the sedimentary record provides a robust proxy for the timing of the first rise in atmospheric $\mathrm{O}_{2}$.}

The photolysis of $\mathrm{SO}_{2}$ by UV light fractionates $\mathrm{S}$ isotopes according to mass laws that deviate substantially from other equilibrium and kinetic processes [1], which is termed mass anomalous fractionation (MAF), and can be described using the statistic $\Delta^{33} \mathrm{~S}$ :

$$
\Delta^{33} S \approx \delta^{33} S-\left(0.515 \times \delta^{34} S\right)
$$

where $\delta^{33} S$ and $\delta^{34} S$ are the normalized ratios (in parts per thousand) of ${ }^{33} S$ to ${ }^{32} \mathrm{~S}$ and ${ }^{34} \mathrm{~S}$ to ${ }^{32} \mathrm{~S}$ respectively (see Methods). In this notation, non-zero $\Delta^{33} \mathrm{~S}$ values indicate the anomalous enrichment (positive) or depletion (negative) of ${ }^{33} \mathrm{~S}$ relative to its expected abundance based on simple mass fractionation relationships.

In the modern atmosphere, $\mathrm{SO}_{2}$ photolysis is suppressed by $\mathrm{O}_{3}$, which is derived from $\mathrm{O}_{2}$ and absorbs UV radiation at key wavelengths. The expression of MAF in the modern is further limited by the chemistry of $\mathrm{O}_{2}$, which, through reduction-oxidation reactions in the atmosphere and surface environments, can homogenize the photolysis products and erase MAF. Together, these constraints have been used to link the preservation of large S-MAF $\left(\Delta^{33} \mathrm{~S}\right.$ from -5 to $+12 \%$ ) in rocks older than $2.33 \mathrm{Ga}$ [2] to extremely low concentrations of atmospheric $\mathrm{O}_{2}\left(<10^{-5}\right.$ times present atmospheric level; [3]).

Despite having a framework for the interpretation of S-MAF, key questions remain about sulfur cycle mass balance. Since the bulk Earth is characterized by a specific abundance pattern of S isotopes, the relative enrichment of ${ }^{33} \mathrm{~S}$ (reported as a positive $\Delta^{33} \mathrm{~S}$ value) should be balanced by a relative depletion in ${ }^{33} \mathrm{~S}$ (negative $\Delta^{33} \mathrm{~S}$ ) so that the total mass of $\mathrm{S}$ in the system retains a $\Delta^{33} \mathrm{~S}$ approximately equal to zero (bulk Earth). Assuming that the crust has the same $\Delta^{33} \mathrm{~S}$ as the bulk Earth $[4,5]$, the mass balance hypothesis holds that the bulk Archean crust has a $\Delta^{33} \mathrm{~S} \approx 0$ despite atmospheric processes that generate $S$ compounds with $\Delta^{33} S \neq 0$ since both photolysis products (i.e. the carriers of both positive and negative $\Delta^{33} \mathrm{~S}$ values) must be simultaneously deposited if the input and output fluxes of $\mathrm{S}$ are close to being in balance. 
In contrast to mass balance expectations, several studies have hypothesized that the bulk $\Delta^{33} \mathrm{~S}$ composition of Archean crust $\left(\Delta^{33} \mathrm{~S}_{A C}\right)$ is greater than zero [6, 7]. This idea is based on compilations of $\Delta^{33} \mathrm{~S}$ measurements of Archean-age rocks that tend to show more positive than negative values $[6,7]$. This hypothesis would require that the photolysis product with a negative $\Delta^{33} \mathrm{~S}$ would have had to preferentially accumulate in a $\mathrm{S}$ reservoir other than the crust (e.g., the mantle; [8]). If correct, this would imply that $\Delta^{33} \mathrm{~S}$ variations in igneous materials can be used to trace the recycling of continental crust in the mantle [8]. Additionally, a $\Delta^{33} \mathrm{~S}_{A C}>0$ would imply that the geologic record of $\Delta^{33} \mathrm{~S}$ in marine sedimentary rocks would be a poor recorder of the timing of atmospheric oxygenation $[6,7]$. This is because, even after atmospheric processes cease to generate S-MAF due to high $\mathrm{pO}_{2}$, the weathering of ancient sulfide minerals formed during times of low $\mathrm{pO}_{2}$ would still transfer sulfur with an anomalous $\Delta^{33} \mathrm{~S}$ value to the ocean, where it can be re-incorporated into the rock record. As most sulfur cycling obeys canonical mass-dependent fractionation laws, the lag between the rise of atmospheric $\mathrm{O}_{2}$ and the disappearance of $\Delta^{33} \mathrm{~S}$ anomalies may be as long as 10 to 100 million years depending upon, among other things, the value of $\Delta^{33} \mathrm{~S}_{A C}$ [7]. Such long lag times would significantly blur our understanding of the timing of the first rise in atmospheric $\mathrm{O}_{2}$.

To test for mass balance in the Archean $\mathrm{S}$ cycle (i.e., to evaluate the idea that $\Delta^{33} \mathrm{~S}_{A C}>0$ ), one requires a robust means to determine $\Delta^{33} \mathrm{~S}_{A C}$ that integrates over large volumes of Archean crust. While a large number of $\Delta^{33} \mathrm{~S}$ measurements of Archean-aged rocks have been made ( $\mathrm{n}>$ 3500 ; references in Supplementary Table S1), using these analyses to infer $\Delta^{33} \mathrm{~S}_{A C}$ poses several challenges. For example, the number of measurements per geographic locality and their temporal resolution are not standardized between studies, which necessitates the use of a statistical weighting procedure to combine different measurements (e.g., [9]). Also, many of the existing $\Delta^{33} \mathrm{~S}$ data come from specific sulfur-rich lithotypes, which raises questions about their relevance to the bulk isotopic composition of the crust. Additional evidence for facies and texture-specific $\Delta^{33} \mathrm{~S}$ variations $[10,11,12,13]$ adds further complications as both sampling and analysis techniques can introduce large biases. Together, these factors challenge the straightforward analysis of $\Delta^{33} \mathrm{~S}$ 
compilations to infer $\Delta^{33} \mathrm{~S}_{A C}$.

\section{Approach and selected field sites}

We took an alternative approach to estimating $\Delta^{33} \mathrm{~S}_{A C}$ that relies on measurements of sulfur in modern rivers that flow over Archean crust to more equitably integrate over the requisite large spatial scales. Presently, the majority of S supplied to surface environments is transferred to the oceans as dissolved sulfate in rivers [14], which reflects the high solubility and rapid dissolution kinetics of common S-bearing minerals as well as the large oxidizing capacity of the modern atmosphere [15]. Since riverine sulfate is sourced from the nearly quantitative weathering of S-bearing minerals contained in the underlying crust, it retains information about their $\Delta^{33} \mathrm{~S}$ composition [16]. Thus, in river catchments underlain by exclusively Archean-aged rocks, the $\Delta^{33} \mathrm{~S}$ of riverine sulfate can be used as a new constraint on $\Delta^{33} \mathrm{~S}_{A C}$.

Due to its potential to provide an unbiased estimate of $\Delta^{33} \mathrm{~S}_{A C}$ integrated over large spatial scales, the analysis of riverine sulfate is a valuable approach to evaluate mass balance in the Archean sulfur cycle. However, its effective use requires additional considerations. For example, biological sulfur cycling may modify the isotopic composition of riverine sulfate [17]. However, modern microbial processes only minimally impact $\Delta^{33} \mathrm{~S}[18]$, preserving information about $\Delta^{33} \mathrm{~S}_{A C}$, but, potentially, not $\delta^{34} \mathrm{~S}_{A C}$. In addition, the contribution of sulfate from rainwater and other non-crustal sources might bias measurements towards a $\Delta^{33} \mathrm{~S}$ of $0 \%$ because they reflect modern (or relatively recent) sulfur. However, the relative contribution of non-crustal sources, including any anthropogenic inputs, is readily quantifiable.

To constrain $\Delta^{33} \mathrm{~S}_{A C}$, we sampled surface $(n=42)$ and groundwaters $(n=2)$ draining the Archean-age Superior Craton in Southern Canada (Fig. 1; table S2). This region is ideal for this task because it features large areas of exclusively Archean-aged rocks that are known to contain sulfide minerals with non-zero $\Delta^{33} \mathrm{~S}$ [19]. The rivers we sampled have a range of catchment areas (individual areas $=40$ to $2.5 \times 10^{4} \mathrm{~km}^{2}$; total area $=1 \times 10^{5} \mathrm{~km}^{2}$ ) and are underlain by variable proportions of Archean-aged sedimentary, igneous, and metamorphic rocks (Fig. 1). We note 
that, relative to average Archean crust [20], the proportions of rock types expected and observed [19] to carry S-MAF are over-represented at our study site (Fig. 1). Additionally, they are dominantly Neoarchean in age, which is an era when $\Delta^{33} \mathrm{~S}$ variations exhibit a large range [21]. In order to evaluate whether or not the results represent Archean crust globally, we supplemented our Canadian data with analyses of rivers $(n=5)$ and groundwaters $(n=3)$ from the Campbellrand carbonate platform in South Africa (Supporting Materials; fig. S1 and table S3).

For all samples, sulfate was extracted from filtered water using ion-exchange chromatography and analyzed for its $\delta^{34} \mathrm{~S}$ and $\Delta^{33} \mathrm{~S}$ composition using Multi-Collector Inductively Coupled Plasma Mass Spectrometry [22]. This technique is very sensitive and well suited for studying rivers, which typically have low sulfate concentrations. Replicate analyses constrain analytical uncertainties to be 0.1 and $0.2 \%(1 \sigma)$ for $\delta^{34} \mathrm{~S}$ and $\Delta^{33} \mathrm{~S}$ respectively. While our analytical uncertainty for $\Delta^{33} \mathrm{~S}$ is large relative to fluorination-based methods (0.2 vs. $0.02 \%$; e.g., [1]), it is small relative to the anomalies observed in the local Archean-aged rocks across the Superior (-1 to $+2.6 \%$; [19]) and Kaapvaal Cratons $(-4$ to $+10 \%$; $[12,13])$.

\section{Results from Canadian and South African rivers}

In surface and groundwaters collected across the Superior Craton field area (Fig. 1), the measured $\Delta^{33} \mathrm{~S}$ values are not significantly different from zero (Fig. 2). This result suggests that, at the $>10 \mathrm{~km}^{2}$ scale, Archean crust is not characterized by a large positive $\Delta^{33} \mathrm{~S}$ anomaly. This result is consistent with our measurements from South Africa, which show riverine $\Delta^{33} \mathrm{~S}$ values that are also zero within uncertainty (fig. S1). We did observe a positive $\Delta^{33}$ S anomaly in one of the three South African groundwater samples (fig. S1). This groundwater sample was from a shallow aquifer in $\sim 2.53$ Ga Cambellrand platform carbonates, which show positive $\Delta^{33} \mathrm{~S}$ values in carbonate-associated sulfate [23]. As local groundwaters sample sulfate from a relatively smaller volume of rock relative to large rivers, our data are, overall, consistent with $\Delta^{33} \mathrm{~S}_{A C} \approx 0$. 


\section{Dissolved sulfate mixing model}

To evaluate the impact of non-crustal sources on our measurements of $\Delta^{33} \mathrm{~S}$ in rivers draining the Superior Craton, we used a mixing model where riverine sulfate is assumed to be sourced from crustal sulfur as well as natural and anthropogenic non-crustal sources (see Methods). The relative contribution of non-crustal sulfur (atmospheric deposition and urban runoff) was constrained using combined mass balances of chloride and sulfate ions along with measurements of the fluxweighted average rainwater composition from 14 stations nearby our sites (fig. S2) and constrained assumptions on the composition of urban runoff. To solve for $\Delta^{33} \mathrm{~S}_{A C}$ based on our source apportionments, non-crustal sources were assumed to have $\Delta^{33} \mathrm{~S}$ values ranging from -0.1 to $+0.1 \%$ o (i.e., consistent with the trend in the data depicted in Fig. 2a). To account for uncertainties in our end-member definitions and analytical measurements, we used a Monte-Carlo approach yielding a probability distribution of $\Delta^{33} \mathrm{~S}_{A C}$ estimated for each river. Samples where the estimated contribution of non-crustal sulfur exceeds $\sim 50 \%$ of the total sulfur budget (Fig. 2) have limited statistical power to constrain $\Delta^{33} \mathrm{~S}_{A C}$ and yield spurious mixing model results (e.g., $\Delta^{33} \mathrm{~S}_{A C}=-1000 \%$ ). As a result, we do not include these samples in our catchment-area weighted estimate of $\Delta^{33} \mathrm{~S}_{A C}$ (see below). For our chosen end-member constraints and observed analytical uncertainty, $\sim 75 \%$ of our dataset has a sufficiently high proportion of crustal sulfur to meaningfully constrain $\Delta^{33} \mathrm{~S}_{A C}$.

The results of our mixing model show that the limited variation observed in the $\Delta^{33} \mathrm{~S}$ values of riverine sulfate is not due to mixing with sulfate derived from non-crustal sources (Fig. 2a) or, alternatively, the weathering of Proterozoic rocks deposited after the rise of oxygen (Fig. 2b). Instead, our measurements reflect $\Delta^{33} \mathrm{~S}_{A C}$ values of the underlying crust that are approximately equal to zero. We note that riverine $\delta^{34} \mathrm{~S}$ is more variable (fig. S3), potentially reflecting the effects of sulfur cycling within the catchments (e.g., [17]) or contributions from urban runoff (Supporting Materials; fig. S3). While our mixing model assumes that sulfate is conservative, loss due to sulfate reduction or biosynthesis would not bias our estimate of $\Delta^{33} \mathrm{~S}_{A C}$ as those fractionations are mass-dependent, and would instead only increase the uncertainty of our estimate as a result of overestimating non-crustal contributions. 
By combining rivers with sufficiently high proportions of crustal S into a single catchmentarea weighted average, we estimated $\Delta^{33} \mathrm{~S}_{A C}$ to be $-0.09 \pm 0.3 \%$ (Fig. 3). Based on these results, the estimate of $\Delta^{33} \mathrm{~S}_{A C}$ made by [6] is permissible $(+0.5 \%$; exceedance probability $=0.05)$, but higher estimates given by [7] are unlikely $(+1$ to $+5 \%$; exceedance probabilities $=0.005$ and $5 \times 10^{-7}$, respectively). Since our estimate of $\Delta^{33} \mathrm{~S}_{A C}$ comfortably encompasses $0 \%$, it gives support to the notion that the $\Delta^{33} \mathrm{~S}$ of Archean-aged crust is equal to zero; and consequently we infer that - despite the substantial MAF that characterizes geological samples- the Archean sulfur cycle was mass balanced (Fig. 3).

\section{Implications for atmospheric oxygenation}

These results have valuable implications for the use of $\Delta^{33} \mathrm{~S}$ as a tracer of the Archean crust and a proxy for atmospheric $p O_{2}$. Values of $\Delta^{33} \mathrm{~S}_{A C} \approx 0 \%$ are consistent with the topology of an Archean $\mathrm{S}$ cycle wherein the majority of $\mathrm{S}$ added to surface environments by weathering and volcanic activity was returned to the crust by pyrite burial without the selective transfer of ${ }^{33} \mathrm{~S}$ depleted components to the mantle [8]. Based on observations of limited variability in the $\Delta^{33} S$ composition of sulfate in rivers draining Archean crust, we also concluded that the weathering of Archean crust does not presently transfer sulfate with a large positive $\Delta^{33} \mathrm{~S}$ anomaly to the oceans (Figs. 2-3). While we observed one dissolved sulfate sample with an anomalous $\Delta^{33}$ S value (e.g., Supplementary Figure S2), it is limited to local groundwater sourced from carbonate rock. Similar observations of $\Delta^{33} \mathrm{~S}$ anomalies in dissolved sulfate in the literature are also limited to groundwater environments that source sulfur from small volumes of crust [16]. Since any of the large $\left(>7 \mathrm{~km}^{2}\right)$ river catchments observed in our study are inconsistent with a $\Delta^{33} S_{A C}$ greater than $1 \%$, we do not expect crustal recycling at a global scale to generate a significant lag between the cessation of S-MAF genesis in the atmosphere and its disappearance in the sedimentary record $[6,7]$.

Our results do not preclude an Archean crust with a small $\Delta^{33} \mathrm{~S}$ anomaly. However, we expect that the magnitude of the associated crustal recycling effect, which depends on the value of $\Delta^{33} \mathrm{~S}_{A C}$ [7], would be too small to be interpreted as evidence for negligible $\mathrm{pO}_{2}$ (i.e., $<0.3 \% 0$ ). 
Similarly, while our field area does include intrusive igneous rocks, they are less abundant than in average Archean crust (Fig. 1) and would have also contributed to riverine sulfate fluxes in the past. Moreover, individual rivers that sample areas underlain by larger proportions of surificial rocks relative to the total average (up to $>98 \%$ meta-sedimentary rocks) do not show evidence for large $\Delta^{33} \mathrm{~S}$ anomalies. Overall, our work supports the hypothesis that the disappearance of $\Delta^{33} \mathrm{~S}$ anomalies in sedimentary rocks provides a robust proxy for the timing of atmospheric oxygenation $[1,2]$.

\section{Methods}

Sample Collection Samples were collected from riverbanks using a polypropylene syringe. Prior to filtering the samples with a $0.2 \mu \mathrm{m}$ porosity nylon filter, the syringe was rinsed with three syringe-volumes of river water. After discarding the first $\sim 10 \mathrm{~mL}$ of filtered water, the remainder was collected into two $15 \mathrm{~mL}$ polypropylene vials. One vial was preserved with approximately 20 $\mu \mathrm{L}$ of high-purity concentrated $\mathrm{HNO}_{3}$ dispensed from a Teflon dropper.

Solute Concentrations To measure major element concentrations, we injected a $4 \mathrm{~mL}$ aliquot from each un-acidified sample into a dual-channel Dionex Ion Chromatograph with parallel anion and cation columns at the Caltech Center For Environmental Analysis. The instrument was calibrated with a set of synthetic standards and precision/accuracy were checked by repeated analysis of the ION-915 river water reference material (Environment Canada).

Sulfate-sulfur isotope measurements To measure the $\delta^{34} \mathbf{S}_{V-C D T}$ and $\delta^{33} \mathbf{S}_{V-C D T}$ of sulfate, we purified sulfate from $\sim 1-10 \mathrm{~mL}$ of sample using an anion exchange resin following established protocols [22, 23]. Before separation, all samples were evaporated to dryness within a clean laboratory. The sample residue was then re-dissolved in $0.5 \% \mathrm{HCl}$ and introduced into a column of AG1X8 resin following [23]. After elution from the columns, the samples were evaporated to dryness and then re-dissolved in 5\% $\mathrm{HNO}_{3}$. Before analysis, all samples were diluted and mixed with 
a sodium hydroxide solution to match the sodium and sulfate concentrations of the bracketing standard. The samples were then analyzed using a Thermo Neptune Plus multi-collector inductively coupled plasma mass spectrometer (MC-ICP-MS) at Caltech using sample-standard bracketing to correct for instrumental drift and mass bias following [22]. Replicate extraction and analysis of a seawater standard was preformed to ensure accuracy between analytical sessions. After analysis, $\Delta^{33} \mathrm{~S}$ values were calculated from measured $\delta^{33} \mathrm{~S}$ and $\delta^{34} \mathrm{~S}$ as:

$$
\Delta^{33} S=\delta^{\prime 33} S-0.515 \times \delta^{\prime 34} S
$$

where $\delta^{\prime 3 X} \mathrm{~S}$ is given by:

$$
\delta^{\prime 3 X} S=1000 \times \ln \left(\frac{\delta^{3 X} S}{1000}+1\right)
$$

Superior Craton Rainwater Chemistry Time series of the major element composition and mass fluxes of rainfall were taken from the NAtChem database (accessed at ec.gc.ca/natchem). Specifically, we used daily samples collected throughout 2011 from the 14 closest stations to our study sites. For each station, we calculated a precipitation-amount weighted annual average rainwater concentration for each solute, which represents the expected concentration of river water assuming that rainwater was the sole solute source (fig. S2). The range of annually-averaged concentrations observed between the 14 stations was used to represent the uncertainty in rainwater contributions for subsequent mixing calculations.

High concentrations of chloride (i.e. up to 19 times greater than the maximum rainwater concentration) and sodium to chloride ratios approximately equal to one imply a significant contribution of anthropogenic deicing salts to the dissolved load for some samples (see below; fig. S2). This hampers the use of chloride as a simple independent check for the proportion of the dissolved load sourced from rainwater based on the NAtChem database. Fortunately the lowest measured sulfate concentrations in river waters were similar to our predicted rainwater concentrations, supporting the inference that estimates of rainwater concentrations provide meaningful constraints on river chemistry (fig. S2).

Rainwater $\mathrm{SO}_{4}$ to $\mathrm{Cl}$ ratios can be temporally variable, but tend to be elevated relative to the 
$\mathrm{SO}_{4} / \mathrm{Cl}$ of seawater, which, in the form of aerosols, is thought to be a main solute source for rainwaters [24]. Typically, uncontaminated rainwater samples show a factor of $\sim 2$ enrichment in $\mathrm{SO}_{4} / \mathrm{Cl}$ relative seawater as a result of biogenic $\mathrm{S}$ aerosols [24]. In contrast, the observed annual mean $\mathrm{SO}_{4} / \mathrm{Cl}$ of rainwaters near our study site are enriched relative to seawater by a factor of $\sim 91$. We attribute such a high enrichment to anthropogenic contamination from some combination of fossil fuel burning and ore smelting. As a result, correcting river water data for the solutes sourced from rainwaters implicitly accounts for some anthropogenic contamination.

Superior Craton Urban Runoff Chemistry The chemical composition of some river samples suggested a solute source associated with anthropogenic de-icing salts (fig. S2 and Table S2). For example, samples collected from streams that drain urbanized areas in the city of Thunder Bay (Lakehead and Madeline) show highly enriched $\mathrm{Cl}$ concentrations and $\mathrm{Na}$ to $\mathrm{Cl}$ ratios close to 1. Since de-icing salts are widely used in urban areas in cold climates, we considered $\mathrm{Cl}$ concentrations and $\mathrm{Na}$ to $\mathrm{Cl}$ ratios as general markers for contamination from "urban runoff", including solutes not directly sourced from de-icing salts.

The amount of $\mathrm{Cl}$ derived from urban runoff can be calculated as the difference between measured riverine concentrations and average rainwater concentrations (from NAtChem) as there are no substantial evaporite deposits present within our study site (Fig. 1). For other solutes, the contribution of urban runoff is calculated as:

$$
X_{R}=X_{C}+X_{A}+\left(C l_{U} \times \frac{X}{C l}{ }_{U}\right)
$$

where the subscripts refer to the mass of solute $(\mathrm{X})$ present in river water $(\mathrm{R})$ and derived from crustal weathering (C), rainwater (A), and urban runoff (U). To apply equation (4) to apportion the sulfate budget, we constrained the $\mathrm{SO}_{4}$ to $\mathrm{Cl}$ ratio of urban runoff using measurements of road salts from [25]. This range of $\mathrm{SO}_{4}$ to $\mathrm{Cl}$ values (0.001 to 0.01$)$ assumes that there are no other $\mathrm{S}$ sources besides road salt in urban runoff. As a sensitivity analysis, we also test an urban runoff $\mathrm{SO}_{4}$ to $\mathrm{Cl}$ end-member ratio an order of magnitude higher than road salt (i.e., 0.1) in our isotopic mixing model (see below). However, trends apparent in our dataset imply that the $\mathrm{SO}_{4}$ to $\mathrm{Cl}$ ratio 
of urban runoff is low. For example, samples with the highest contributions of urban runoff (based on $\mathrm{Na}$ and $\mathrm{Cl}$ mass budgets) show the lowest $\mathrm{SO}_{4}$ to $\mathrm{Cl}$ ratios $(<0.1)$.

Assuming limited evaporation, the mixing of solute masses can be approximated by mixing solute concentrations (denoted below using brackets). As a result, equation (4) can be re-written to solve for the proportion of sulfate derived from crustal weathering $\left(f_{C}\right)$ where:

$$
f_{C}=\frac{\left[\mathrm{SO}_{4}\right]_{R}-\left[\mathrm{SO}_{4}\right]_{A}-\left([\mathrm{Cl}]_{U} \times \frac{\mathrm{SO}_{4}}{\mathrm{Cl}} \mathrm{U}\right)}{\left[\mathrm{SO}_{4}\right]_{R}}
$$

$\Delta^{33} S$ Mixing Model By grouping together both non-crustal S sources (i.e., atmospheric deposition and urban runoff), the $\Delta^{33} S$ budget can be written as a two-component mixing problem where:

$$
\Delta^{33} S_{R} \approx\left(f_{C} \times \Delta^{33} S_{C}\right)-\left(\left(1-f_{C}\right) \times \Delta^{33} S_{A+U}\right)
$$

Grouping together both non-crustal sources (i.e., rainwater and urban runoff) is justified as they are both expected to have $\Delta^{33} S \approx 0$ on account of them incorporating predominately modern sulfur. While atmospheric sulfate aerosols derived from volcanic gases injected into the stratosphere can display non-zero $\Delta^{33} S$ values [26], these values are small relative to Archean rocks, our study site is far from any active volcanism, and previous estimates suggest that volcanogenic sulfate makes up a small proportion of the sulfate in local rainwaters [27]. Alternatively, the smelting of sulfurrich ores derived from local Archean rocks could contribute $S$ with an anomalous $\Delta^{33} S$ to the atmosphere. As a sensitivity test, we allow the $\Delta^{33} S$ of the non-crustal end-member to range from -0.1 to $+0.1 \%$ in order to account for uncertainty in the exact $\Delta^{33} S$ of non-crustal sources. This range is consistent with our data that show high proportions of non-crustal sulfur (Fig. 2a).

As written, equation (6) yields an approximate solution as it ignores non-linearities associated with using $\delta^{33} \mathrm{~S}$ and $\delta^{34} \mathrm{~S}$ in end-member mixing problems. The error incurred by this approximation increases with the difference in $\delta^{34} \mathrm{~S}$ values between end-members. Measurements of local rainwaters (+2 to +9 \%; $[27,28])$ and bedrock $(-0.4$ to $+6 \% 0 ;[19])$ yield similar $\delta^{34}$ S, which implies negligible errors of $<0.004 \%$ when using equation 6 . While the $\delta^{34} \mathrm{~S}$ of urban runoff is unknown, regressing the mean estimates of the proportion of urban runoff-derived $\mathrm{S}$ against the 
measured $\delta^{34} \mathrm{~S}$ for each river sample and extrapolating to $100 \%$ urban runoff yields a $\delta^{34} \mathrm{~S}$ of $41 \pm$ $6 \%$ (fig. S3), which is sufficiently close in magnitude to the other end-members for the approximate form of the mixing equation (i.e., equation 6) to yield accurate results (error $<0.04 \%$ ). As a result, we use the approximate form of the mixing equation in all mixing calculations.

All together, our mixing analysis uses the flux-weighted average concentration of rainwaters (from NatChem) and measured $\left[\mathrm{SO}_{4}\right],[\mathrm{Cl}]$, and $\Delta^{33} \mathrm{~S}$ values in river waters (this study) along with assumptions of the $\mathrm{SO}_{4}$ to $\mathrm{Cl}$ ratio of urban runoff (0.001 to 0.1$)$ and the combined $\Delta^{33} \mathrm{~S}$ value of rainwater and urban runoff contributions (-0.1 to $0.1 \%$ ). For our Monte Carlo analysis, the river and rainwater measurements are represented as normal distributions while the assumed endmember ratios are represented as uniform distributions. All mixing results are constrained such that the fractional contribution of each end-member must be between 0 and 1 . The mixing analysis is performed using $10^{7}$ random draws from each a priori distribution. Replicate simulations were tested to ensure negligible variations in our area-weighted estimate of $\Delta^{33} \mathrm{~S}_{A C}$.

This mixing model analysis generates a distribution of possible $\Delta^{33} S_{A C}$ values given our measurements, their analytical uncertainties, and our selected a priori end-member values. To determine an area-weighted estimate for the entire study region, we first culled the data to remove rivers where the estimated proportion of crustal sulfur was too low to meaningfully constrain $\Delta^{33} \mathrm{~S}_{A C}$. Specifically, we removed data where the standard deviation of $\Delta^{33} \mathrm{~S}_{A C}$ estimates was $>1 \%$, which roughly corresponds to mean estimate of less than 50\% crustal sulfur. All real simulations from the culled dataset were used to calculated a weighted mean and weighted standard deviation where the weighting factors corresponded to the catchment areas. Additionally, we fit the a posteriori distribution of $\Delta^{33} S_{A C}$ values for each catchment to a normal distribution and re-sampled them proportionally to their catchment areas. The random samples generated from the sub-set of catchments with sufficiently high $f_{C}$ were concatenated and fit with a $t$ distribution to calculate exceedance probabilities (i.e., the probability that a random number generated from the a posteriori distribution of $\Delta^{33} S_{A C}$ would exceed a threshold value).

The results shown in Fig. 3 depict our estimates $\Delta^{33} S_{A C}$ assuming that the upper bound of 
the $\mathrm{SO}_{4}$ to $\mathrm{Cl}$ ratio of urban runoff is 0.01 . Increasing this value by a factor of 10 decreases the number of samples that meet our acceptance criteria $(\sigma<1 \%)$ from $75 \%$ to $63 \%$ of sampled river catchments. Additionally, it changes the area-weighted estimate of $\Delta^{33} S_{A C}$ from $-0.09 \pm 0.3 \%$ o to $0.0 \pm 0.3 \%$. As these two estimates are statistically indistinguishable, we consider our results to be robust despite having imperfect constraints on the end-member composition of urban runoff.

Data Availability All original data generated as part of this study are available in Supplementary Tables S2 and S3 and online from the PANGEA repository. The Canadian precipitation chemistry analyses are available online at ec.gc.ca/natchem. Complied analyses of the Sulfur isotopic composition of Archean sulfides are available in the original publications (see citations in Table $\mathrm{S} 1)$.

Code Availability The code used to perform the data analysis shown in Figure 3 can be accessed at github.com/torres-lab.

\section{References}

[1] Farquhar, J., Bao, H. \& Thiemens, M. Atmospheric Influence of Earth's Earliest Sulfur Cycle. Science 289, 756-758 (2000).

[2] Luo, G. et al. Rapid oxygenation of Earths atmosphere 2.33 billion years ago. Science Advances 2, e1600134 (2016).

[3] Pavlov, A. \& Kasting, J. Mass-Independent Fractionation of Sulfur Isotopes in Archean Sediments: Strong Evidence for an Anoxic Archean Atmosphere. Astrobiology 2, 27-41 (2002).

[4] Labidi, J., Cartigny, P. \& Moreira, M. Non-chondritic sulphur isotope composition of the terrestrial mantle. Nature 501, 208-211 (2013). 
[5] Wing, B. A. \& Farquhar, J. Sulfur isotope homogeneity of lunar mare basalts. Geochimica et Cosmochimica Acta 170, 266-280 (2015).

[6] Farquhar, J. \& Wing, B. A. Multiple sulfur isotopes and the evolution of the atmosphere. Earth and Planetary Science Letters 213, 1-13 (2003).

[7] Reinhard, C. T., Planavsky, N. J. \& Lyons, T. W. Long-term sedimentary recycling of rare sulphur isotope anomalies. Nature 497, 100-103 (2013).

[8] Cabral, R. a. et al. Anomalous sulphur isotopes in plume lavas reveal deep mantle storage of Archaean crust. Nature 496, 490-493 (2013).

[9] Keller, C. B. \& Schoene, B. Statistical geochemistry reveals disruption in secular lithospheric evolution about 2.5 Gyr ago. Nature 485, 490-493 (2012).

[10] Partridge, M. A., Golding, S. D., Baublys, K. A. \& Young, E. Pyrite paragenesis and multiple sulfur isotope distribution in late Archean and early Paleoproterozoic Hamersley Basin sediments. Earth and Planetary Science Letters 272, 41-49 (2008).

[11] Ono, S., Beukes, N. J. \& Rumble, D. Origin of two distinct multiple-sulfur isotope compositions of pyrite in the 2.5 Ga Klein Naute Formation, Griqualand West Basin, South Africa. Precambrian Research 169, 48-57 (2009).

[12] Farquhar, J. et al. Pathways for Neoarchean pyrite formation constrained by massindependent sulfur isotopes. Proceedings of the National Academy of Sciences 110, 1763817643 (2013).

[13] Fischer, W. W. et al. SQUID-SIMS is a useful approach to uncover primary signals in the Archean sulfur cycle. Proceedings of the National Academy of Sciences 111, 5468-5473 (2014).

[14] Gaillardet, J., Viers, J. \& Dupré, B. Trace elements in river waters. Treatise on geochemistry 5, 225-272 (2003). 
[15] Johnson, J. E., Gerpheide, a., Lamb, M. P. \& Fischer, W. W. O 2 constraints from Paleoproterozoic detrital pyrite and uraninite. Geological Society of America Bulletin 126, 813-830 (2014).

[16] Li, L. et al. Sulfur mass-independent fractionation in subsurface fracture waters indicates a long-standing sulfur cycle in Precambrian rocks. Nature Communications 13252 (2016).

[17] Turchyn, A. V., Tipper, E. T., Galy, A., Lo, J. K. \& Bickle, M. J. Isotope evidence for secondary sulfide precipitation along the Marsyandi River, Nepal, Himalayas. Earth and Planetary Science Letters 374, 36-46 (2013).

[18] Johnston, D. T. Multiple sulfur isotopes and the evolution of Earth's surface sulfur cycle. Earth-Science Reviews 106, 161-183 (2011).

[19] Bekker, A. et al. Atmospheric Sulfur in Archean Komatiite-Hosted Nickel Deposits. Science 326, 1086-1089 (2009).

[20] Goodwin, A. M. Principles of Precambrian geology (Academic Press, 1996).

[21] Halevy, I., Johnston, D. T. \& Schrag, D. P. Explaining the structure of the Archean massindependent sulfur isotope record. Science 329, 204-207 (2010).

[22] Paris, G., Sessions, A. L., Subhas, A. V. \& Adkins, J. F. MC-ICP-MS measurement of $\delta^{34}$ S and $\Delta^{33} \mathrm{~S}$ in small amounts of dissolved sulfate. Chemical Geology 345, 50-61 (2013).

[23] Paris, G., Adkins, J. F., Sessions, A. L., Webb, S. M. \& Fischer, W. W. Neoarchean carbonateassociated sulfate records positive 33S anomalies. Science 346, 739-742 (2014).

[24] Stallard, R. \& Edmond, J. Geochemistry of the Amazon 1. Precipitation chemistry and the marine contribution to the dissolved load at the time of peak discharge. Journal of geophysical Research 86, 9844-9858 (1981). 
[25] Price, J. R. \& Szymanski, D. W. The effects of road salt on stream water chemistry in two small forested watersheds, catoctin mountain, maryland, usa. Aquatic geochemistry 20, 243265 (2014).

[26] Baroni, M., Thiemens, M. H., Delmas, R. J. \& Savarino, J. Mass-independent sulfur isotopic compositions in stratospheric volcanic eruptions. Science 315, 84-87 (2007).

[27] Nriagu, J. O. \& Coker, R. D. Isotopic composition of sulfur in precipitation within the Great Lakes Basin. Tellus A 2826, 365-375 (1978).

[28] Caron, F., Tessier, A., Kramer, J. R., Schwarcz, H. P. \& Rees, C. E. Sulfur and oxygen isotopes of sulfate in precipitation and lakewater, Quebec, Canada. Applied Geochemistry 1, 601-606 (1986).

Acknowledgments M.A.T. acknowledges support from the Caltech Texaco Postdoctoral fellowship and the California Alliance for Graduate Education and the Professoriate (AGEP). This work was supported from funds supplied by the David and Lucile Packard Foundation, a Caltech GPS Division Discovery Award (W.W.F), and a grant from the National Science Foundation (EAR1349858) to W.W.F and J.F.A. This project benefited from the use of instrumentation made available by the Caltech Environmental Analysis Center. All authors acknowledge helpful comments provided by Dr. Boswell Wing on an earlier draft of this manuscript.

Author Contributions G.P. and M.A.T conducted the laboratory analyses. All authors contributed to the sample collection, data analysis, and manuscript preparation.

Competing interests The authors have no competing financial or non-financial interests. 


\section{Figure Captions}

Figure 1 Maps showing the location, sampling localities, and bedrock geology of the Superior Craton study area. (a) Geologic map showing the bedrock geology divided into five classes (see figure legend) and displayed only for areas within sampled river catchments (yellow points). (b) Inset shows the area within larger North American region. (c) the relative proportions of plutonic (intrusive igneous and metaigneous) and surficial (sedimentary, metasedimentary, volcanic) rocks within average Archean crust [20] and exposed in all of our study catchments combined.

Figure 2 Sulfur isotope measurements of Canadian Rivers. (a) The relationship between sulfate $\Delta^{33} \mathrm{~S}$ and the fraction of sulfate derived from crustal weathering $\left(f_{C}\right)$. The river samples (white circles) are compared with $\Delta^{33} \mathrm{~S}$ values of local Archean rocks (gray squares; [19]) and potential non-crustal sources (black bar). (b) The relationship between sulfate $\Delta^{33} \mathrm{~S}$ and the fraction of the catchment area underlain by Archean bedrock. The black lines show linear regressions with 68\% confidence intervals where either $f_{C}$ (a) or Archean catchment area (b) is the explanatory variable. Error bars on each point indicate one standard deviation of the analytical uncertainty.

Figure 3 Inferred $\Delta^{33} \mathrm{~S}_{A C}$ from analyses of Canadian Rivers. The black probability density func-

tion (pdf) shows the catchment-area weighted average of the a posteriori distributions of $\Delta^{33} \mathrm{~S}_{A C}$ from our mixing model for each river sample (shown as white points with 1 standard deviation uncertainty bounds). In dark gray, we show a pdf of a compilation of Archean-aged sulfide minerals (references in table S1). The dashed line is the $\Delta^{33} \mathrm{~S}_{A C}$ estimate of [6]. The rectangle is the range of $\Delta^{33} \mathrm{~S}_{A C}$ estimates from [7]. The estimate of $\Delta^{33} \mathrm{~S}_{A C}$ from our river data $(-0.09 \pm 0.3 \% 0)$ is consistent with the mass balance expectation of $\Delta^{33} \mathrm{~S}_{A C}=0$. 
C. Average Archean Crust

Surficial Plutonic

Sampled Area

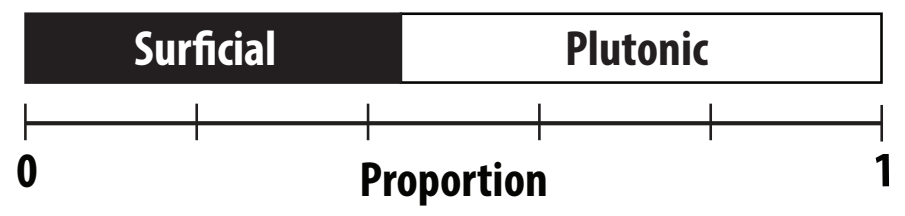

Archean Volcanics Archean (Meta)sedimentary Archean Intrusive $\bigcirc$ Sampling sites

- Paleoproterozoic Lake Nipigon
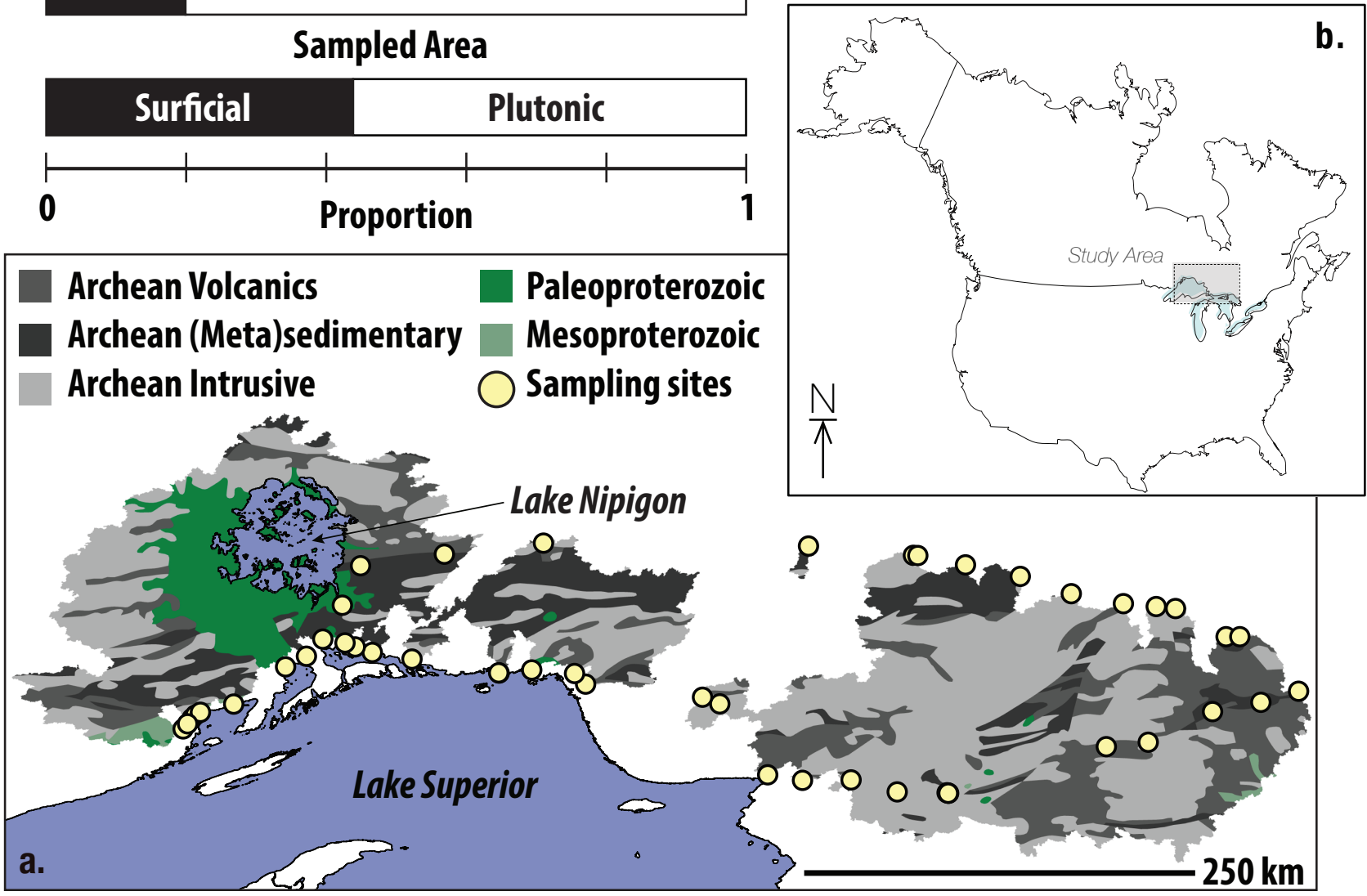


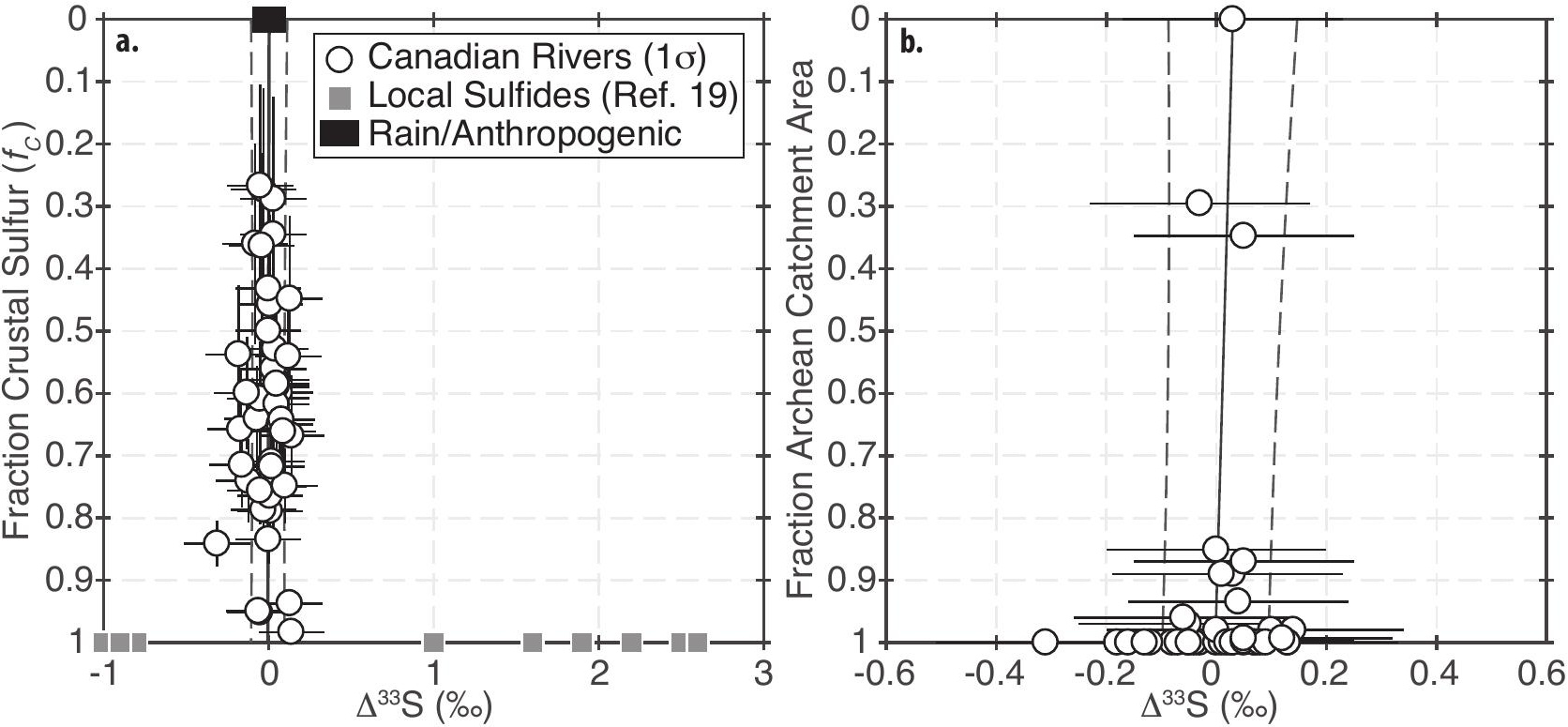




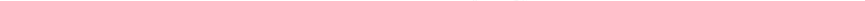




\title{
Supplementary Information for: "Riverine evidence for isotopic mass balance in the Earth's early sulfur cycle"
}

\author{
Mark A. Torres, Guillaume Paris, Jess F. Adkins, \& Woodward W. Fischer
}

Supplementary Text

Figs. S1 to S3

Table S1 to S3

References

South Africa field site River and groundwater samples in South Africa were collected from the Neoarchean Campbellrand-Malmani platform (table S3). River water samples from this region are consistent with $\Delta^{33} S_{A C} \approx 0 \%$ (fig. S1). Similarly, all but one of the groundwater samples also yield $\Delta^{33} S$ values within two standard deviation of zero. Like other $\Delta^{33} S$ anomalies reported in the literature (e.g., Li et al., 2016), our single groundwater sample with a $\Delta^{33} S$ anomaly $(+1.8 \%$ ) is presumed to average a small volume of rock and thus is not representative of the bulk Archean crust. Consistent with this, river waters within the same region do not show $\Delta^{33} S$ anomalies (fig. $\mathrm{S} 1$ ). Since rainwater concentration data is unavailable for the South Africa field sites, it is not possible to more quantitatively constrain $\Delta^{33} S_{A C}$ using these samples.

Superior Craton $\delta^{34} \mathbf{S}$ River water samples collected from the Superior Craton field site show $\delta^{34} \mathrm{~S}$ values that range from +2.7 to $+11.4 \%$ (table S2). Broadly, this range is consistent with the ranges observed in local rainwaters (+2 to $+9 \%$; Nriagu and Coker, 1978; Caron et al., 1986) and bedrock (-0.4 to $+6 \%$; Bekker et al., 2009). However, a few samples exhibit $\delta^{34} \mathrm{~S}$ values higher than either the rain or bedrock end-members. As these high $\delta^{34} \mathrm{~S}$ samples are also enriched in $\mathrm{Cl}$, the sulfur isotopic enrichment may reflect contributions from urban runoff with a high $\delta^{34} \mathrm{~S}$. Consistent with this, the predicted proportions of urban runoff derived $\mathrm{S}$ are positively correlated with the measured $\delta^{34} \mathrm{~S}$ values (fig. S3). While there is some scatter in this relationships, it may be due to variable proportions of crustal and rain-derived sulfur with distinct $\delta^{34} \mathrm{~S}$ values. Alternatively, some sulfate liberated by rock weathering may be exported from the catchment as a reduced phase (e.g. organic sulfur) as a result of modern $\mathrm{S}$ cycling, which could cause mass-dependent $\mathrm{S}$ isotopic fractionation. Such loss of sulfate would cause us to overestimate the fraction of sulfate sourced from atmospheric deposition and urban runoff using Equation 5. This overestimation along with any mass-dependent fractionation would not significantly bias our estimate of $\Delta^{33} S_{A C}$, but instead only add to its uncertainty. 


\section{References}

L. Li, B. A. Wing, T. H. Bui, J. M. McDermott, G. F. Slater, S. Wei, G. Lacrampe-Couloume, and B. Sherwood Lollar. Sulfur mass-independent fractionation in subsurface fracture waters indicates a long-standing sulfur cycle in Precambrian rocks. Nature Communications, page 13252, 2016. doi: 10.1038/ncomms 13252 .

J. O. Nriagu and R. D. Coker. Isotopic composition of sulfur in precipitation within the Great Lakes Basin. Tellus A, 2826(May):365-375, 1978. ISSN 0280-6495. doi: 10.3402/tellusa.v30i4.10356.

Francois Caron, Andre Tessier, James R. Kramer, Henry P. Schwarcz, and Charles E. Rees. Sulfur and oxygen isotopes of sulfate in precipitation and lakewater, Quebec, Canada. Applied Geochemistry, 1(5):601-606, 1986. ISSN 08832927. doi: 10.1016/0883-2927(86)90067-3.

Andrey Bekker, Mark E Barley, Marco L Fiorentini, Olivier J Rouxel, Douglas Rumble, and Stephen W Beresford. Atmospheric Sulfur in Archean Komatiite-Hosted Nickel Deposits. Science, 326(5956):1086-1089, 2009. ISSN 0036-8075. doi: 10.1126/science.1177742.

Nicole L. Cates and Stephen J. Mojzsis. Chemical and isotopic evidence for widespread Eoarchean metasedimentary enclaves in southern West Greenland. Geochimica et Cosmochimica Acta, 70 (16):4229-4257, 2006. ISSN 00167037. doi: 10.1016/j.gca.2006.05.014.

James Farquhar, Huiming Bao, and Mark Thiemens. Atmospheric Influence of Earth's Earliest Sulfur Cycle. Science, 289(5480):756-758, 8 2000. doi: 10.1126/science.289.5480.756.

James Farquhar, Marc Peters, David T. Johnston, Harald Strauss, Andrew Masterson, Uwe Wiechert, and Alan J. Kaufman. Isotopic evidence for Mesoarchaean anoxia and changing atmospheric sulphur chemistry. Nature, 449(7163):706-709, 2007. doi: 10.1038/nature06202.

James Farquhar, John Cliff, Aubrey L Zerkle, Alexey Kamyshny, Simon W Poulton, Mark Claire, David Adams, and Brian Harms. Pathways for Neoarchean pyrite formation constrained by mass-independent sulfur isotopes. Proceedings of the National Academy of Sciences, 110(44): 17638-17643, 2013. ISSN 1091-6490. doi: 10.1073/pnas.1218851110.

Woodward W Fischer, David a Fike, Jena E Johnson, Timothy D Raub, Yunbin Guan, Joseph L Kirschvink, and John M Eiler. SQUID-SIMS is a useful approach to uncover primary signals in the Archean sulfur cycle. Proceedings of the National Academy of Sciences, 111(15):54685473, 2014. doi: 10.1073/pnas.1322577111.

Eugene G. Grosch and Nicola McLoughlin. Paleoarchean sulfur cycle and biogeochemical surface conditions on the early Earth, Barberton, South Africa. Earth and Planetary Science Letters, 377-378:142-154, 2013. doi: 10.1016/j.eps1.2013.06.035.

Qingjun Guo, Harald Strauss, Alan J. Kaufman, Stefan Schröder, Jens Gutzmer, Boswell Wing, Margaret A. Baker, Andrey Bekker, Quesheng Jin, Sang Tae Kim, and James Farquhar. Reconstructing Earth's surface oxidation across the Archean-Proterozoic transition. Geology, 37(5): 399-402, 2009. ISSN 00917613. doi: 10.1130/G25423A.1. 
B. M. Guy, S. Ono, J. Gutzmer, A. J. Kaufman, Y. Lin, M. L. Fogel, and N. J. Beukes. A multiple sulfur and organic carbon isotope record from non-conglomeratic sedimentary rocks of the Mesoarchean Witwatersrand Supergroup, South Africa. Precambrian Research, 216-219: 208-231, 2012. doi: 10.1016/j.precamres.2012.06.018.

Guixing Hu, Douglas Rumble, and Pei Ling Wang. An ultraviolet laser microprobe for the in situ analysis of multisulfur isotopes and its use in measuring Archean sulfur isotope massindependent anomalies. Geochimica et Cosmochimica Acta, 67(17):3101-3117, 2003. ISSN 00167037. doi: 10.1016/S0016-7037(02)00929-8.

Gareth Izon, Aubrey L. Zerkle, Iadviga Zhelezinskaia, James Farquhar, Robert J. Newton, Simon W. Poulton, Jennifer L. Eigenbrode, and Mark W. Claire. Multiple oscillations in Neoarchaean atmospheric chemistry. Earth and Planetary Science Letters, 431:264-273, 2015. doi: 10.1016/j.eps1.2015.09.018.

B. S. Kamber and M. J. Whitehouse. Micro-scale sulphur isotope evidence for sulphur cycling in the late Archean shallow ocean. Geobiology, 5(1):5-17, 2007. ISSN 14724677. doi: 10.1111/j.1472-4669.2006.00091.x.

Alan J Kaufman, David T Johnston, James Farquhar, Andrew L Masterson, Timothy W Lyons, Steve Bates, Ariel D Anbar, Gail L Arnold, Jessica Garvin, and Roger Buick. Late archean biospheric oxygenation and atmospheric evolution. Science, 317(5846):1900-1903, 2007.

Florian Kurzweil, Mark Claire, Christophe Thomazo, Marc Peters, Mark Hannington, and Harald Strauss. Atmospheric sulfur rearrangement 2.7 billion years ago: Evidence for oxygenic photosynthesis. Earth and Planetary Science Letters, 366:17-26, 2013. doi: 10.1016/j.eps1.2013.01.028.

G. Luo, S. Ono, N. J. Beukes, D. T. Wang, S. Xie, and R. E. Summons. Rapid oxygenation of Earths atmosphere 2.33 billion years ago. Science Advances, 2(5):e1600134, 2016. doi: 10.1126/sciadv.1600134.

S. J. Mojzsis, C. D. Coath, J. P. Greenwood, K. D. McKeegan, and T. M. Harrison. Massindependent isotope effects in Archean (2.5 to $3.8 \mathrm{Ga}$ ) sedimentary sulfides determined by ion microprobe analysis. Geochimica et Cosmochimica Acta, 67(9):1635-1658, 2003. ISSN 00167037. doi: 10.1016/S0016-7037(00)00059-0.

Alice Montinaro, Harald Strauss, Paul R D Mason, Desiree Roerdink, Carsten M??nker, Ulrich Schwarz-Schampera, Nicholas T. Arndt, James Farquhar, Nicolas J. Beukes, Jens Gutzmer, and Marc Peters. Paleoarchean sulfur cycling: Multiple sulfur isotope constraints from the Barberton Greenstone Belt, South Africa. Precambrian Research, 267:311-322, 2015.

Hiroshi Ohmoto, Yumiko Watanabe, Hiroaki Ikemi, Simon R. Poulson, and Bruce E. Taylor. Sulphur isotope evidence for an oxic Archaean atmosphere. Nature, 442(7105):908-911, 2006. doi: 10.1038/nature05044. 
Shuhei Ono, Jennifer L. Eigenbrode, Alexander A. Pavlov, Pushker Kharecha, Douglas Rumble, James F. Kasting, and Katherine H. Freeman. New insights into Archean sulfur cycle from massindependent sulfur isotope records from the Hamersley Basin, Australia. Earth and Planetary Science Letters, 213(1-2):15-30, 2003. ISSN 0012821X. doi: 10.1016/S0012-821X(03)002954.

Shuhei Ono, Boswell Wing, Douglas Rumble, and James Farquhar. High precision analysis of all four stable isotopes of sulfur $\left({ }^{32} \mathrm{~S},{ }^{33} \mathrm{~S},{ }^{34} \mathrm{~S}\right.$ and $\left.{ }^{36} \mathrm{~S}\right)$ at nanomole levels using a laser fluorination isotope-ratio-monitoring gas chromatographymass spectrometry. Chemical Geology, 225(1-2): 30-39, 1 2006. doi: 10.1016/j.chemgeo.2005.08.005.

Shuhei Ono, Alan J. Kaufman, James Farquhar, Dawn Y. Sumner, and Nicolas J. Beukes. Lithofacies control on multiple-sulfur isotope records and Neoarchean sulfur cycles. Precambrian Research, 169(1-4):58-67, 2009a. ISSN 03019268. doi: 10.1016/j.precamres.2008.10.013.

Shuhei Ono, Nicolas J. Beukes, and Douglas Rumble. Origin of two distinct multiple-sulfur isotope compositions of pyrite in the 2.5 Ga Klein Naute Formation, Griqualand West Basin, South Africa. Precambrian Research, 169(1-4):48-57, 2009b. ISSN 03019268. doi: 10.1016/j.precamres.2008.10.012.

Dominic Papineau, S. J. Mojzsis, C. D. Coath, J. A. Karhu, and K. D. McKeegan. Multiple sulfur isotopes of sulfides from sediments in the aftermath of Paleoproterozoic glaciations. Geochimica et Cosmochimica Acta, 69(21):5033-5060, 2005. ISSN 00167037. doi: 10.1016/j.gca.2005.07.005.

D. Papineau and S. J. Mojzsis. Mass-independent fractionation of sulfur isotopes in sulfides from the pre-3770 Ma Isua Supracrustal Belt, west Greenland. Geobiology, 4(4):227-238, 2006. ISSN 14724677. doi: 10.1111/j.1472-4669.2006.00083.x.

Michaela A. Partridge, Suzanne D. Golding, Kim A. Baublys, and Elisa Young. Pyrite paragenesis and multiple sulfur isotope distribution in late Archean and early Paleoproterozoic Hamersley Basin sediments. Earth and Planetary Science Letters, 272(1-2):41-49, 2008. ISSN 0012821X. doi: 10.1016/j.epsl.2008.03.051.

Pascal Philippot, Mark van Zuilen, and Claire Rollion-Bard. Variations in atmospheric sulphur chemistry on early Earth linked to volcanic activity. Nature Geoscience, 5(9):668-674, 2012. doi: 10.1038/ngeo1534.

Desiree L. Roerdink, Paul R D Mason, Martin J. Whitehouse, and Thomas Reimer. High-resolution quadruple sulfur isotope analyses of 3.2Ga pyrite from the Barberton Greenstone Belt in South Africa reveal distinct environmental controls on sulfide isotopic arrays. Geochimica et Cosmochimica Acta, 117:203-215, 2013. doi: 10.1016/j.gca.2013.04.027.

Emilie Thomassot, Jonathan ONeil, Don Francis, Pierre Cartigny, and Boswell A. Wing. Atmospheric record in the Hadean Eon from multiple sulfur isotope measurements in Nuvvuagittuq Greenstone Belt (Nunavik, Quebec). Proceedings of the National Academy of Sciences, 112(3): 707-712, 2015. doi: 10.1073/pnas.1419681112. 
Christophe Thomazo, M. Ader, J. Farquhar, and P. Philippot. Methanotrophs regulated atmospheric sulfur isotope anomalies during the Mesoarchean (Tumbiana Formation, Western Australia). Earth and Planetary Science Letters, 279(1-2):65-75, 2009. doi: 10.1016/j.epsl.2008.12.036.

Yuichiro Ueno, Shuhei Ono, Douglas Rumble, and Shigenori Maruyama. Quadruple sulfur isotope analysis of ca. 3.5 Ga Dresser Formation: New evidence for microbial sulfate reduction in the early Archean. Geochimica et Cosmochimica Acta, 72(23):5675-5691, 2008. doi: 10.1016/j.gca.2008.08.026.

Martin J. Whitehouse, Balz S. Kamber, Christopher M. Fedo, and Aivo Lepland. Integrated $\mathrm{Pb}$ - and $\mathrm{S}$-isotope investigation of sulphide minerals from the early Archaean of southwest Greenland. Chemical Geology, 222(1-2):112-131, 2005. ISSN 00092541. doi: 10.1016/j.chemgeo.2005.06.004.

Aubrey L. Zerkle, Mark W. Claire, Shawn D. Domagal-Goldman, James Farquhar, and Simon W. Poulton. A bistable organic-rich atmosphere on the Neoarchaean Earth. Nature Geoscience, 5 (5):359-363, 2012. doi: 10.1038/ngeo1425.

I. Zhelezinskaia, A. J. Kaufman, J. Farquhar, and J. Cliff. Large sulfur isotope fractionations associated with Neoarchean microbial sulfate reduction. Science, 346(6210):742-744, 2014. doi: 10.1126/science. 1256211 . 


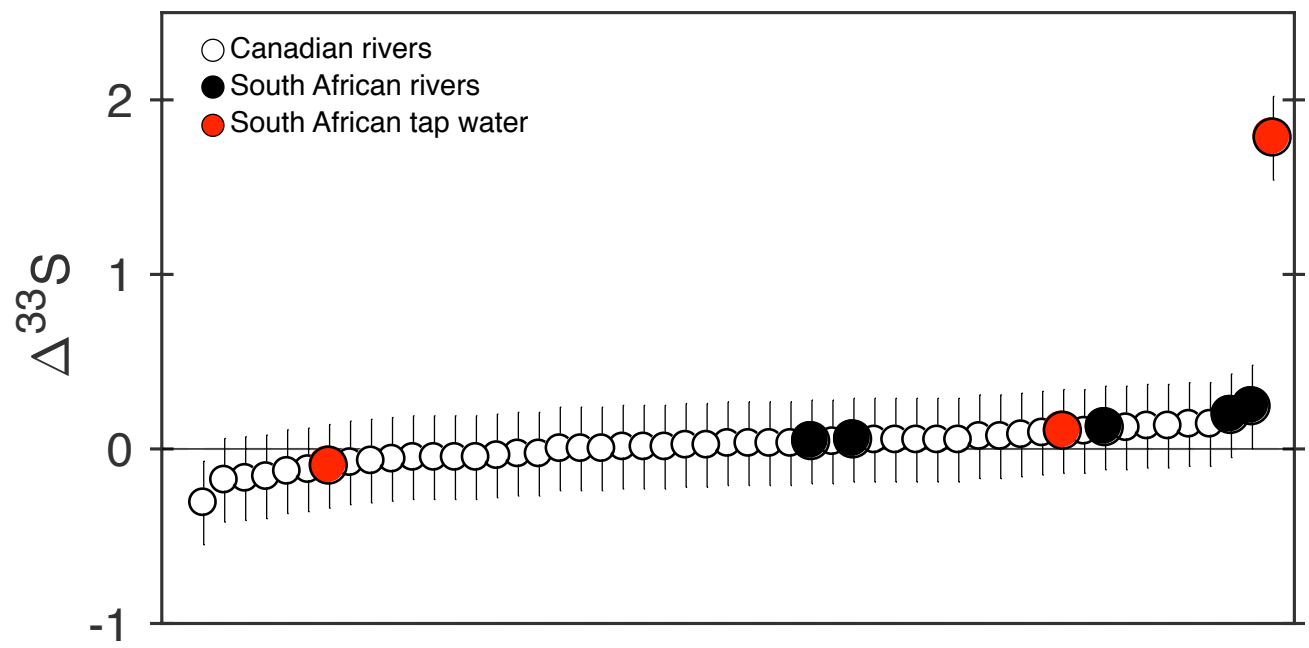

Figure S1: Sulfur isotopic ratios of Canadian and South African samples. A majority of dissolved sulfate sourced from the weathering of Archean rocks has a $\Delta^{33} S \approx 0 \%$. While one groundwater sample from a carbonate aquifer has a higher value, we hypothesized that this sample averages over a small volume of rock and thus not representative of the bulk crust. Error bars represent one standard deviation of the analytical uncertainty. 


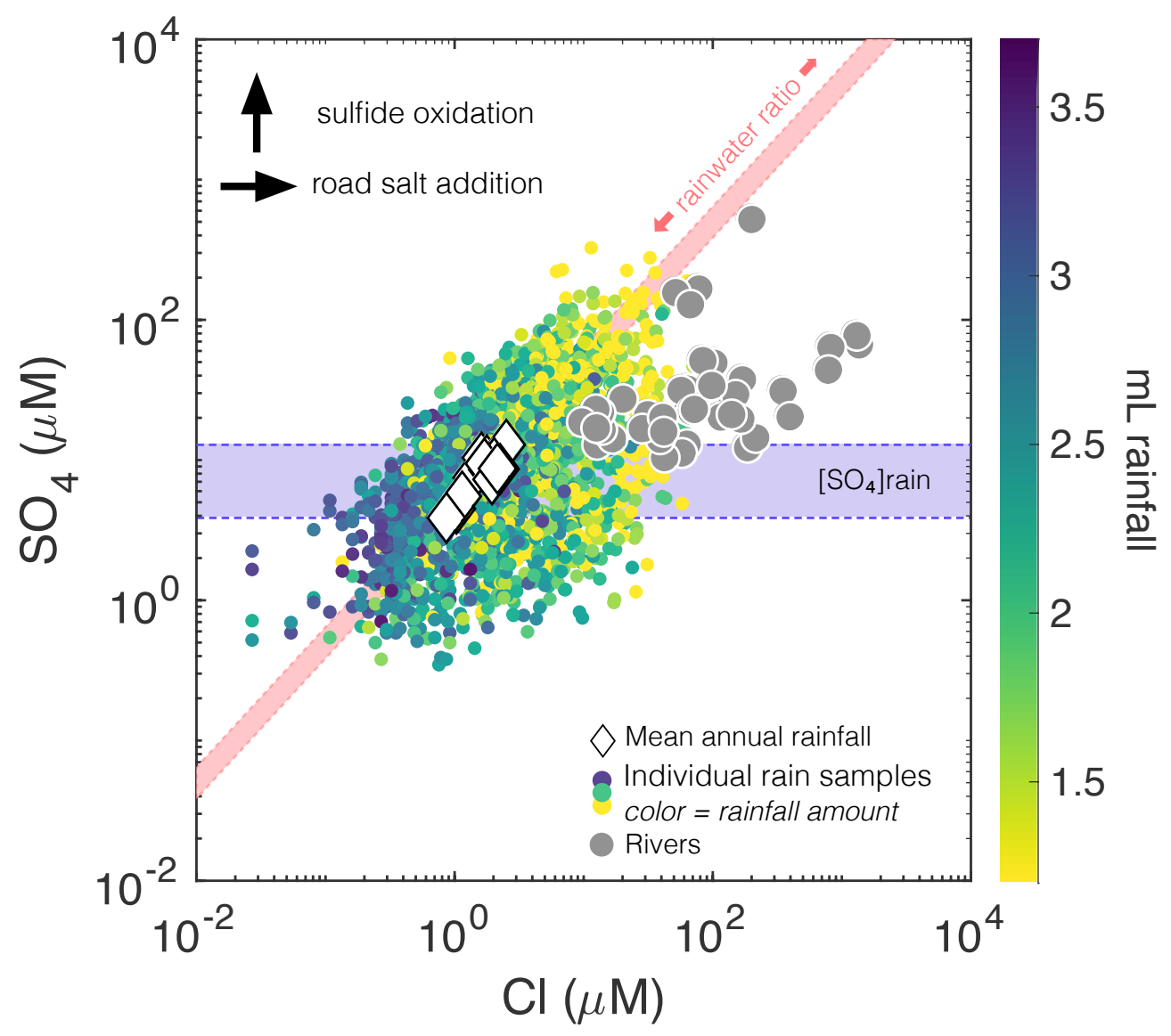

Figure S2: The chloride and sulfate concentrations of daily rainwater samples (colored points) compared with precipitation-weighted mean annual rainfall (diamonds) and river waters (gray circles) in the Great Lakes region of Canada. The daily rainfall samples are color-coded based on the volume of precipitation that fell during the collection day. We assumed that the sulfate concentration of mean annual rainfall represents the minimum concentration of river water and that excess sulfate in river water derives from rock weathering. 


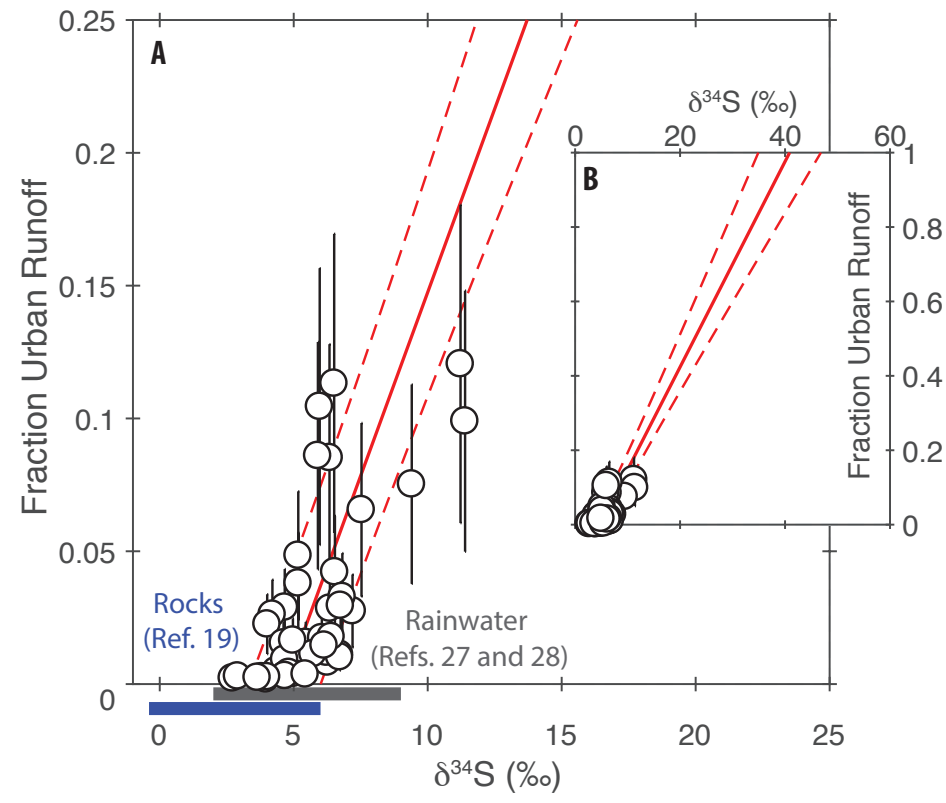

Figure S3: $\delta^{34} \mathrm{~S}$ of Canadian Rivers. (a) Measured $\delta^{34} \mathrm{~S}$ values of riverine sulfate and the inferred proportion of sulfate sourced from urban runoff (mean and one standard deviation). The red trend line refers to a linear regression using the mean proportions of urban runoff sourced sulfate. (b) Same as in (a) but showing the predicted $\delta^{34} \mathrm{~S}$ of urban runoff based on the liner regression. The dash lines show the $68 \%$ confidence interval. 
Table S1: Sulfide Mineral $\Delta^{33}$ S Compilation

\begin{tabular}{ccc}
\hline First Author & Year & Citation \\
\hline Cates & 2006 & (Cates and Mojzsis, 2006) \\
Farquhar & $2000,2007,2013$ & (Farquhar et al., 2000, 2007, 2013) \\
Fischer & 2014 & (Fischer et al., 2014) \\
Grosch & 2013 & (Grosch and McLoughlin, 2013) \\
Guo & 2009 & (Guo et al., 2009) \\
Guy & 2012 & (Guy et al., 2012) \\
Hu & 2003 & (Hu et al., 2003) \\
Izon & 2015 & (Izon et al., 2015) \\
Kamber & 2007 & (Kamber and Whitehouse, 2007) \\
Kaufman & 2007 & (Kaufman et al., 2007) \\
Kurzweil & 2013 & (Kurzweil et al., 2013) \\
Luo & 2016 & (Luo et al., 2016) \\
Mojzis & 2003 & (Mojzsis et al., 2003) \\
Montinaro & 2015 & (Montinaro et al., 2015) \\
Ohmoto & 2006 & (Ohmoto et al., 2006) \\
Ono & $2003,2006,2009 \mathrm{a}, 2009 \mathrm{~b}$ & (Ono et al., 2003, 2006, 2009a,b) \\
Papineau & 2005,2008 & (Papineau et al., 2005; Papineau and Mojzsis, 2006) \\
Partridge & 2009 & (Partridge et al., 2008) \\
Philippot & 2012 & (Philippot et al., 2012) \\
Roerdink & 2013 & (Roerdink et al., 2013) \\
Thomassot & 2015 & (Thomassot et al., 2015) \\
Thomazo & 2009 & (Thomazo et al., 2009) \\
Ueno & 2008 & (Ueno et al., 2008) \\
Whitehouse & 2005,2008 & (Whitehouse et al., 2005) \\
Zerkle & 2012 & (Zerkle et al., 2012) \\
Zhelezinskaia & 2014 & (Zhelezinskaia et al., 2014) \\
\hline & & \\
& &
\end{tabular}


Table S2: Superior Craton Data

\begin{tabular}{|c|c|c|c|c|c|c|c|c|}
\hline Name & Area $\left(\mathrm{km}^{2}\right)$ & Latitude & Longitude & $\mathrm{Cl}(\mu \mathrm{M})$ & $\mathrm{SO}_{4}(\mu \mathrm{M})$ & $\delta^{34} \mathrm{~S}(\% 0)$ & $\Delta^{33} \mathrm{~S}(\%)$ & $\%$ Archean \\
\hline Kaministiquia River & 7705.0 & 48.340 & -89.333 & 358.7 & 30.3 & 7.5 & -0.2 & 91 \\
\hline Lakehead & 150.1 & 48.422 & -89.265 & 1402.9 & 64.8 & 11.2 & 0.0 & 88 \\
\hline Madeline & 43.2 & 48.451 & -89.235 & 1339 & 75.5 & 11.4 & 0.0 & 89 \\
\hline Current River & 603.0 & 48.469 & -89.199 & 144.2 & 27.8 & 6.4 & 0.1 & 98 \\
\hline Mackenzie River & 358.4 & 48.535 & -88.941 & 64.9 & 22.5 & 5.5 & 0.1 & 86 \\
\hline Wolf River & 603.2 & 48.822 & -88.539 & 32.1 & 20.6 & 6.3 & 0.1 & 34 \\
\hline Black Sturgeon River & 2709.4 & 48.905 & -88.376 & 842.3 & 62.1 & 9.4 & 0.0 & 30 \\
\hline Helen Lake & 25589.4 & 49.037 & -88.250 & 406.8 & 19.9 & 6.5 & 0.0 & 57 \\
\hline Gorge Creek & 39.6 & 49.302 & -88.099 & 13 & 12.6 & 4.4 & 0.0 & 0 \\
\hline Blackwater River & 484.6 & 49.609 & -87.957 & 190.6 & 12 & 6.3 & 0.0 & 100 \\
\hline Longlac & 1690.3 & 49.784 & -86.539 & 64.7 & 12.7 & 7.2 & -0.1 & 100 \\
\hline Skunk River & 176.6 & 49.761 & -84.484 & 65 & 31.4 & 6.7 & -0.1 & 100 \\
\hline Mattawishkwia River & 1034.3 & 49.686 & -83.633 & 220.2 & 14.1 & 5.9 & 0.0 & 100 \\
\hline Missinaibi River & 10363.6 & 49.615 & -83.265 & 17.1 & 13.9 & 5.2 & 0.0 & 100 \\
\hline Opasatika River & 1337.2 & 49.525 & -82.841 & 59.1 & 11 & 4.7 & 0.0 & 100 \\
\hline Kapuskasing River & 3372.8 & 49.391 & -82.445 & 173.9 & 36.5 & 4.2 & 0.0 & 100 \\
\hline Poplar Rapids River & 126.1 & 49.289 & -81.784 & 43.3 & 10.2 & 4.0 & -0.1 & 100 \\
\hline Mattagami River (1) & 9041.5 & 49.275 & -81.636 & 104.6 & 48 & 6.2 & 0.0 & 98 \\
\hline Hunta & 598.0 & 49.058 & -81.244 & 40 & 13.8 & 4.6 & 0.1 & 100 \\
\hline Fredrick House River & 3300.6 & 49.059 & -81.138 & 79.9 & 162.2 & 3.8 & -0.1 & 97 \\
\hline Driftwood River & 531.7 & 48.634 & -80.682 & 158.9 & 20.7 & 6.5 & 0.1 & 100 \\
\hline Night Hawk Lake & 2327.7 & 48.549 & -80.975 & 52.9 & 153 & 4.0 & -0.1 & 96 \\
\hline Mattagami River (2) & 6335.1 & 48.476 & -81.351 & 58.1 & 30.7 & 6.7 & 0.1 & 98 \\
\hline Opishing River & 87.9 & 48.239 & -81.848 & 29.1 & 16.4 & 5.3 & -0.2 & 100 \\
\hline Groundhog River & 3680.5 & 48.203 & -82.173 & 69.9 & 21.8 & 6.1 & -0.1 & 100 \\
\hline N. Chapleau Lake & 139.9 & 47.845 & -83.407 & 118.9 & 19.8 & 6.8 & 0.1 & 100 \\
\hline S. Chapleau Lake & 296.1 & 47.842 & -83.396 & 154 & 28.6 & 6.8 & 0.0 & 100 \\
\hline Chapleau Hotel & $\mathrm{NaN}$ & 47.842 & -83.398 & 205.6 & 508.4 & 2.7 & 0.1 & $\mathrm{NaN}$ \\
\hline Grazing River & 123.1 & 47.855 & -83.795 & 73.8 & 22.5 & 6.4 & 0.1 & 100 \\
\hline Jackpine River (1) & 1659.4 & 47.945 & -84.153 & 42 & 19.7 & 5.7 & -0.1 & 100 \\
\hline Michipicoten River & 4227.7 & 47.944 & -84.529 & 20.6 & 26.6 & 5.0 & -0.2 & 100 \\
\hline Magpie River & 1958.6 & 47.986 & -84.798 & 85.6 & 50.1 & 4.7 & -0.3 & 100 \\
\hline Depew River & 245.7 & 48.536 & -85.172 & 169 & 19.2 & 5.2 & 0.0 & 100 \\
\hline White River & 1027.2 & 48.588 & -85.307 & 143.2 & 20.7 & 5.2 & -0.1 & 100 \\
\hline Pic tributary & 2168.7 & 48.688 & -86.213 & 68.8 & 125.2 & 2.9 & 0.1 & 100 \\
\hline Pic River & 3702.8 & 48.770 & -86.297 & 13.2 & 19.8 & 4.7 & 0.1 & 100 \\
\hline Little Pic River & 2076.8 & 48.801 & -86.631 & 14.2 & 16.1 & 4.8 & 0.0 & 94 \\
\hline Steel River tributary & 7.1 & 48.775 & -86.882 & 806 & 42.8 & 6.0 & 0.0 & 100 \\
\hline Steel River & 1175.3 & 48.777 & -86.884 & 13.8 & 21.3 & 4.7 & 0.1 & 100 \\
\hline Pays Plat River & 427.6 & 48.882 & -87.560 & 12.7 & 22.5 & 4.0 & 0.1 & 99 \\
\hline Cypress River & 117.7 & 48.934 & -87.865 & 9.9 & 18.3 & 3.6 & 0.1 & 99 \\
\hline Jackpine River (2) & 275.0 & 48.977 & -87.998 & 12.8 & 16.6 & 5.4 & 0.1 & 99 \\
\hline Jackfish River & 463.4 & 49.008 & -88.078 & 42.7 & 15.6 & 6.1 & 0.0 & 85 \\
\hline Best Western Hotel & $\mathrm{NaN}$ & 48.381 & -89.299 & 100.5 & 33.3 & 5.0 & -0.1 & $\mathrm{NaN}$ \\
\hline
\end{tabular}


Table S3: Kaapvaal Craton Data

\begin{tabular}{ccccc}
\hline Name & Latitude & Longitude & $\delta^{34} \mathrm{~S}(\% 0)$ & $\Delta^{33} \mathrm{~S}(\% 0)$ \\
\hline Maroela Guest House & -24.595 & 27.406 & 6.1 & -0.1 \\
Mfolozi River & -28.238 & -31.176 & 6.8 & 0.0 \\
Vryheid B\&B & -27.769 & 30.792 & 9.2 & 0.1 \\
Harts River (1) & -26.383 & 25.910 & 10.4 & 0.2 \\
Rus 'n Bietjie & -28.163 & 23.558 & 7.1 & 1.8 \\
Harts River (2) & -27.571 & 24.743 & 14.3 & 0.0 \\
Elands River & -25.334 & 27.292 & 6.6 & 0.1 \\
Crocodile River & -24.653 & 27.379 & 7.5 & 0.2 \\
\hline
\end{tabular}

